\title{
Çocuklarda Nörojenik Mesanede Antibakteriyel Kateterle Temiz Aralıklı Kateterizasyon Etkinliği
}

\author{
Efficacy of Antibiotic Coated Clean Intermittent Catheterization in Children with Neurogenic Bladder
}

\author{
Onur Telli' ${ }^{1}$ Perviz Haciyev'1, Ali Cansu Bozacı², Emin Mamadov², Mesut Altan², \\ Adil Hüseynov'1, Cesur Samancl ${ }^{3}$, Hasan Serkan Doğan², Tarkan Soygür'1, Berk Burgu', \\ Serdar Tekgül2
}

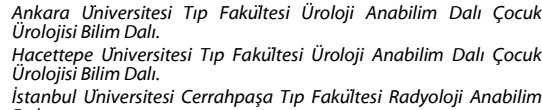

Istanbul Universitesi Cerrahpaşa Tıp Fakültesi Radyoloji Anabilim Dal.

Geliș Tarihi : 08.05.2016• Kabul Tarihi: 14.11.2016

Iletișim

Uz. Dr. Onur Tell

E-posta: onurtelli@yahoo.com

Tel: 03125955564

Ankara Üniversitesi Tıp Fakültesi Cebeci Araștırma ve

Uygulama Hastanesi Üroloji Anabilim Dalı Çocuk Ürolojisi

Bilim Dalı 06590 Cebeci/Ankara
Amaç: Nörojen mesaneli çocuklarda, ürolojik takibin amacı üriner sistem enfeksiyonu riskini ve bununla ilișili böbrek hasarını azaltmaktır. Bu çalıșmada nörojen mesaneli çocuklarda kullanılan antibakteriyel (kitosan) temiz aralıklı kateterlerin standart kateterlere göre idrar yolu enfeksiyonu ve sonuçları açısından karșılaștırılması yapılmıștır.

Gereç ve Yöntemler: Ocak 2007 ile Haziran 2016 tarihleri arasında, iki refere merkezde takip edilen, yașları 6 ile 16 arasında değișen 144 nörojen mesane tanısıyla temiz aralıkı kateterizasyon yapan hasta dosyaları retrospektif olarak tarandı. Grup 1 antibakteriyel kateter kullanan 55 hasta, Grup 2'de standart kateter kullanan 42 hasta ve Grup 3'de ise daha önceden standart kateter kullanan ve daha sonra en az 6 ay süreyle antibakteriyel kateter kullanan 29 hastadan olușmuștur. Olgular ateșli idrar yolu enfeksiyonu ve asemptomatik bakteriüri açısından geriye dönük olarak değerlendirildi. Ayrıca pyelonefrit açısından yüksek riskli olabilecek (grade 3 ve üstü vezikoüreteral reflü varlığı veya nükleer görüntülemede skar varlığı) tanımlanan alt-grupta da, TAK kateterleri arasındaki fark değerlendirilmiștir.

Bulgular: Toplamda 126 hasta (89 kız, 37 erkek) çalıșmaya dahil edildi. Çalıșmaya katılan hastaların ortalama yașı 9.6 \pm 2.6 yıl (6-16 yıl) ve ortalama takip süresi $58 \pm 14$ ay (22-69 ay) olarak bulunmuștur. Her üç grup arasında asemptomatik bakteriüri ve ateșli idrar yolu enfeksiyonu açısından bir fark bulunamamıștır. Riskli grupta ise, ateșli idrar yolu enfeksiyonu ve sintigrafide yeni skar olușumu standart kateter kullanan hastalarda, antibakteriyel kateter kullananlara ve daha sonradan antibakteriyel katetere geçenlere göre daha sık olduğu görülmüștür.

Sonuç: Antibakteriyel ve standart TAK nörojenik mesaneli çocuklarda benzer enfeksiyon oranları ile kullanılabilir. Üriner sistem enfeksiyonu açısından daha riskli kabul edilebilecek gruplarda (grade 3'den büyük vezikoüreteral reflü varlığı, daha önce sintigrafide tanımlanan pyelonefrit bağlı skar veya dilate üreter) antibakteriye kateterler, standart kateterlere göre daha güvenle kullanılabilir.

Anahtar Sözcükler: Temiz Aralıklı Kateterizasyon; Nörojenik Mesane; Idrar Yolu Enfeksiyonu

Aim: The primary goal of urologic management in children with neurogenic bladder is to reduce the risk of urinary tract infection (UTI) and associated renal injury. We aimed to evaluate the use of antibacterial-coated clean intermittent catheterization $(\mathrm{CIC})$ catheters for neurogenic bladder patients in comparison with standard catheters.

Material and Methods: We performed a retrospective study of 144 neurogenic bladder patients aged 6-16 years old who received CIC at two major centers between January 2007 and June 2016. Group 1 consisted of children used antibacterial coated (chitosan) catheter $(n=55)$, group 2 of children used standard CIC without antibacterial $(n=42)$ and group 3 of children used standard CIC returned into antibiotic coated CIC mimimum 6 months $(n=29)$. Febrile urinary tract infection and asymptomatic bacteriuria were evaluated among patients with antibacterial coated or standard catheters. We also focused on a subgroup of patients with high risk of urinary tract infection (grade $3>$ vesicoureteral reflux, previously scar formation in renal scintigraphy).

Results: Totally 126 patients ( 89 female, 37 male) were involved in this study. The mean age of the study group was $9.6 \pm 2.6$ years (range 6 to 16 ) and the mean follow-up $58 \pm 14$ months (min: 22, max: 69). There was no significant difference between three groups for asymptomatic bacteriuria and febrile UTI frequencies. However, febrile UTI frequencies and de nova scar formation in renal scintigraphy were higher in previously defined subgroup of patients with high risk of urinary tract infection in group 2 than group 1 and 3.

Discussion: Both antibiotic coated and standard CIC can be used in children with neurogenic bladder with similar complication rates. Patients with high risk of urinary tract infection (higher than grade 3 vesicoureteral reflux, dilated ureter, previously de nova scar formation in renal scintigraphy) will benefit from antibacterialcoated catheters rather than standard ones.

Key Words: Clean Intermittant Catheterization; Neurogenic Bladder; Urinary Tract Infection 
Temiz aralıklı kateterizasyon (TAK), belli zaman aralıklarında, steril olmaya gerek duymadan, hijyen koşullarına özen göstererek, mesanedeki idrarın, nelaton tipi bir kateterle boşaltılmasıdır (1). Özellikle meningoselli çocukların doğumundan itibaren TAK ve antikolinerjik tedavi yaklaşımının üriner sistem için önemli bir koruma sağladığını ortaya konulmuştur (2). TAK kullanımının üst üriner sistem korunmasında sağladığ1 faydanın yanında işlemin komplikasyonları da önemli bir yer edinmektedir. TAK yapanlarda idrar yolu enfeksiyonu (IYE) en sik rastlanan komplikasyondur. TAK yapılmaya başladığında kateterizasyon başına bakteriüri oranı \%1-3'dür. IYE prevalans1 \%12-88 arasinda değişmektedir (3). Bu enfeksiyonların asemptomatik veya semptomatik olması da önemlidir. Bu çalıșmada nörojenik mesane nedeniyle TAK yapılan hastalarda, antibakteriyel kateterlerin standart kateterlere göre asemptomatik ve semptomatik IYE oranları karşılaşt1rilması amaçlanmıştır. Ayrıca bu çalışmada alt grup olarak IYE açısından yüksek riskli olabilecek (grade 3'den büyük vezikoüreteral reflü, dilate üreter veya pyelonefrite bağlı önceden skarı olan) hastalarda TAK'a bağlı semptomatik veya asemptomatik IYE geçirme oranları araştırılması planlanmıştır.

\section{Gereç ve Yöntemler}

2007 ve 2016 yılları arasında Ankara Üniversitesi ve Hacettepe Üniversitesi Çocuk Ürolojisi Bilim Dallarında 6 ile 16 yaş arasında nörojenik mesane tanısı ile TAK yapan 144 hastanin dosyaları retrospektif olarak incelendi. Ancak 18 olgu kayıtların yetersizliği nedeniyle çalışma dışı bırakılarak 126 olgu çalışmaya alındı. Hastalar kullanılan TAK göre gruplandirildı. Grup 1'de antibakteriyel (kitosan, N-Asetil-D-glukozamin monomerlerinin (Glc-NAc) $\beta-1,4$ bağılyla bağlanması ile oluşmuş) kateter kulla- nan 55 hasta, Grup 2'de standart kateter kullanan 42 hasta ve Grup 3'de ise daha önceden standart kateter kullanan ve daha sonra en az 6 ay süreyle antibakteriyel kateter kullanan 29 hasta dahil edilmiştir. Olguların poliklinik ve laboratuvar kayıtları incelenerek yas, cinsiyet, klinik bulguları, kültür sonuçları, ateşli idrar yolu enfeksiyonu ve asemptomatik bakteriüri geriye dönük olarak değerlendirildi. Ayrıca nörojenik mesane nedeniyle TAK yapan hastalardan, idrar yolu enfeksiyonu açısından Avrupa Üroloji kılavuzlarında belirtildiği üzere pyelonefrit açısından yüksek riskli olabilecek (grade 3'den büyük vezikoüreteral reflü veya nükleer görüntülemede skar varlı̆̆ı) tanımlanan bir alt-grupta da, TAK kateterleri açısından değerlendirilmiștir (4). Çalıșmadaki nörojenik mesane sebebiyle TAK yapan hasta 88 (69.8\%) iken, nörojenik olmayan etyolojik nedenlerden (nonnörojenik mesane, ekstrofi mesane, posterior üretral valv ve diğer) dolayı TAK yapan hasta say1s1 38 (30.2\%) olarak bulunmuștur. TAK yapan hastalarda rutin antibiyotik uygulamamız olmamakla birlikte, vezikoüreteral reflüsü olan ve TAK yapan tüm hastalar supresif antibiyotik tedavisi almaktadır.

Klinik olarak anlamlı, idrar kuiltüründe mililitrede $10^{5}$ koloni ve üzeri mikroorganizma üremesi bulunan ve ateşi olan hastalar IYYE olarak kabul edildi. IYE semptomlan olmayan, rutin kontrollerinde idrar kültüründe üremesi olması asemptomatik bakteriüri olarak kabul edildi (5). İdrar örnekleri idrar kontrolü olmayan hastalarda standart temizliği takiben kateterizasyon yapılarak toplandi. Çalışmada elde edilen veriler değerlendirilirken SPSS (Statistical Package for the Social Sciences, version 15.0 for Windows, SPSS ${ }^{2}$ Inc, Chicago, IL) istatistik analizi programı kullanıldı. Verilerin sıklik ve ortalama \pm standart sapma (SD) değerleri verildi. Oranların karşılaştırılmasında ki-kare testi kullanılmıştır, devamlı değişkenlerin karşılaştırılmasında dağılımın şekline göre t-test, mann-whitney test veya Anova kullanılmışur.

\section{Bulgular}

Çalıșmamıza; Ocak 2007 ve Haziran 2016 tarihleri arasında nörojenik mesane tanisı ile TAK yapan, dosyalarında ayrintilı muayene notları bulunan, idrar yolu enfeksiyonu tedavisi almış veya asemptomatik olarak değerlendirilmiş ve takiplere düzenli olarak katılmış olan 126 hasta alındi. Ortalama takip

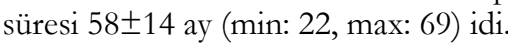
Ortalama hasta yaşı $9.6 \pm 2.6$ yil (6-16) olan 126 hastanın 37'si (\%29.3) erkek, 89 'u (\%70.6) kız idi. Antibakteriyel kateter kullanan 55 hastanın bulunduğu Grup 1, standart kateter kullanan 42 hastanın bulunduğu Grup 2 ve daha önceden standart kateter kullanan ve daha sonra en az 6 ay süreyle antibakteriyel kateter kullanan 29 hastanin bulunduğu Grup 3'te yaş $(\mathrm{p}=0.32)$ ve cinsiyet $(\mathrm{p}=0.55)$ açısından anlamlı bir fark bulunamamıştır (Tablo 1). Grup 1'de 48 (\%87), grup 2'de 37 (\%88), grup 3'te ise $23(\% 79)$ hastada asemptomatik bakteriüri görülürken; grup 1'de 7 (\%12), grup 2'de $8(\% 19)$ ve grup 3'de $3(\% 10)$ febril IYE görülmüştür. Gruplar arasinda asemptomatik bakteriüri $(p=0.18)$ ve febril IYE $(p=0.12)$ açısından istatistiksel olarak anlamlı bir fark bulunamamıștır. Alt grupta ise Grup 1'de 14 (\%66), grup 2'de $11(\% 68)$, grup 3'te ise $7(\% 58)$ hastada asemptomatik bakteriüi; grup 1'de 3 (\%14), grup 2'de 7 (\%43) ve grup 3'de $2(\% 16)$ hastada febril IYY ve grup 1'de $2(\% 9)$, grup 2'de $6(\% 37)$ ve grup 3'de $1(\% 8)$ hastada yeni skar oluşumu görülmüştür. Asemptomatik bakteriüri açısından her üç grup anlamlı bir fark bulanamazken (ki-kare testi, $\mathrm{p}=0.43$ ), febril iye (ki-kare testi, $\mathrm{p}=0.012$ ), ve denovo skar (ki-kare testi, $\mathrm{p}=0.014)$, antibiyotik kaplı katater kullanılan grup 1 ve 3'te anlamlı derecede düşük bulunmuştur.

Tablo 1: Çalışmaya dahil edilen grupların demografik özellikleri

\begin{tabular}{|l|c|c|c|c|}
\hline & Grup 1 (n=55) & Grup 2 (n=42) & Grup 3 (n=29) & P değeri \\
\hline Yaș & $9.3 \pm 2.6$ & $9.7 \pm 2.4$ & $8.3 \pm 2.9$ & $0.32($ Anova) \\
\hline Cinsiyet (E/K) & $17 / 38$ & $12 / 30$ & $8 / 21$ & $0.55(\mathrm{ki}-\mathrm{kare} \mathrm{testi})$ \\
\hline Asemptomatik Bakteriüri & $48(\% 87)$ & $37(\% 88)$ & $23(\% 79)$ & $0.18(\mathrm{ki}-\mathrm{kare}$ testi) \\
\hline Febril IYE & $7(\% 12)$ & $8(\% 19)$ & $3(\% 10)$ & $0.12(\mathrm{ki}-\mathrm{kare}$ testi) \\
\hline
\end{tabular}




\section{Tartıșma}

TAK bulunmasından günümüze kadar, nörojen mesaneli ve işeme disfonksiyonlu hastaların uzun dönem takiplerinde, üst üriner sistemin korunmasinda ve yaşam kalitesinde dramatik bir şekilde iyileşme gözlenmiştir. TAK, artan mesane basıncını düşürmesi, düşuk mesane kompliyansina etkisi ve üst üriner sistemin korunmasina yardimcı olmasindan dolayı, nörojenik ve nörojenik olmayan mesane boşaltım sorunlarında mortalite ve morbiditeyi azaltması açısından çok önemli bir yöntemdir. Bunun yanında TAK uygulanmasi ile beraberinde komplikasyonları da barındırmaktadır. En s1k görülen istenmeyen yan etki üriner sistem enfeksiyonlarıdır (6). IYE teşhisi için çeşitli yöntemlerin kullanılması, TAK farklı malzemelerle yapılması, idrar analizinin farklı sıklıklarda yapılması, enfeksiyon için farklı kriterlerin kabul edilmesi ve supresyon için antibiyotik kullanıp kullanılmaması IYE sıklı̆̆ını etkilemektedir (7).

Wyndaele ve arkadaşları (8) ise nörojen mesaneli hastalarda klasik kateter kullanıp hidrofilik katetere geçen 39 hastayı değerlendirdiği çalışmada, hidrofilik kateterlerin kullanımının kolay ve daha iyi tolere edilebilir olduğunu göstermiştir. Ayrıca uzun süredir klasik kateter kullanan hastalardaki problemler bu hastalarda görulmemis,tir. Hidrofilik kateterlerin bu avantajlarına karşın bazı hastalar ekonomik nedenlerden dolayı bu kateterleri kullanamamaktadır. İkiyüzelli iki nörojen mesaneli, 136 detrüsör myopatisi ve 19 infravezikal obstruksiyonu olan 407 hastanın 1 yıllık takiplerinde; klinik önemi olmayan IYE \%24.5, minimal semptomlu IYE \%58.6, sik semptomlu IYY \%14.3 ve önemli semptomlu hastaları \%2.6 olarak bildirmiştir (9). Başka bir çalışmada ise pyelonefrit insidans1 \%14-37, ürosepsis insidansı ise yaklaşı $\% 3$ oranında bildirilmektedir (10).

TAK yapan hastalarda üriner sistem enfeksiyonunun, uygulama esnasındaki üretral travmaya bağlı mukozal bariyerin görmüş olduğu hasara bağlı geliştiği rapor edilmiştir (11). Ek olarak mesane duvarı rezidü idrarda bakterilere karşı daha duyarlı hale gelmektedir. Rezidü idrarla beraber gerilen mesanede, kapiller oklüzyona bağlı mesane duvarından metabolik ve immün substratların geri dönüşümü engellendiği belirtilmiştir (12). Bu konuda yapılan bir çalışmada TAK ile ilişkili komplikasyonlar düşük olmasına karşın, genellikle yeterli sıklikta kateterizasyon uygulanmaması ile bazı komplikasyonların ortaya çıkabildiği belirtilmektedir (13). IYE, bakterilerin kateter iç tabakasına kolonizasyonu sonrasında oluşturduğu biofilm formasyonu neticesinde de oluşabilmektedir. Kateterlerin özellikle tekrar kullanımında, bakteriler biofilm tabakadan kolayca idrara geçebilmekte ve semptomatik IYE sebep olabilmektedir. (14).

İki refere merkezin kliniklerinde, TAK ile takip edilen nörojenik mesane hastalarının incelemesi ile yapılan bu çalışmada standart hidrofilik kateter kullanan hastalar ile antibakteriyel (kitosan) kateter kullanan hastalar karşılaştırılmıştır. Retrospektif incelemeye rağmen TAK tiplerine bağlı oluşabilecek
IYE (semptomatik veya asemptomatik) araştırıldığı, literatürdeki nadir çalışmalardan biridir. Antibakteriyel kateterlerin ve daha sonradan antibiyotikli katetere geçen hastalardaki asemptomatik bakteriüri ve ateşli IYE enfeksiyon oranları standart hidrofilik kateterlerden farklı olmadığı görülmüştür.

Grade 3'den büyük vezikoüreteral reflü, dilate üreteri olan veya daha önceden sintigrafik olarak gösterilmiş pyelonefrite bağlı skarı olan hastalar, ateşli IYE açısından riskli olarak kabul edilmektedir $(15,16)$. Vezikoüreteral reflüye bağlı dilatasyonu olan hastalarda TAK ile rezidü idrarın boşaltılması güçleşmektedir. Rezidü idrara bağlı olarak da bu hastalarda bakteriyel kolonizasyonu daha kolay gerçekleşmektedir. Gram (+) Staphylococcus aureus ve Gram (-) Pseudomonas aeruginosa ile Escherichia colinnin değerlendirildiği bir çalışmada, kitosan kaplı kateterlerin antiseptik etkinliği gösterilmiștir (17). Rutin antibakteriyel kateter kullanılmasinin bu kolonizasyonu azaltabileceğini düşünmekteyiz.

\section{Sonuç}

Literatürde bu kateterlerin karşılaştırıldığı çalıșma olmamakla birlikte, bu çalıșmada ateşli IYE veya pyelonefrit açısından yüksek risk içeren hastalarda, antibiyotikli kateter kullanılması standart kateter kullananlara göre daha az ateşli IYE geçirilmesi ve daha az yeni skar oluşturduğu görülmüştür. $\mathrm{Bu}$ sonuçların daha geniş kat1lımlı, kontrollü klinik çalışmalarla desteklenmesi gerekmektedir. 


\section{KAYNAKLAR}

1. Di Benedetto P. Clean intermittent selfcatheterization in neuro-urology. Eur J Phys Rehabil Med 2011; 47: 651-659.

2. Amarenco G, Guinet A, Jousse $M$, et al. Pencil and paper test: a new tool to predict the ability of neurological patients to practice clean intermittent self-catheterization. J Urol. 2011; 185:578-582.

3. Wyndaele JJ. Complications of intermittent catheterization: their prevention and treatment. Spinal Cord 2002; 40: 536-541.

4. Tekgul S, Dogan HS, Hoebeke P, et al (2016) Guidelines on Paediatric Urology. European Association of Urology Avaible at: http://uroweb.org/wp-content/uploads/23-Paediatric-Urology_LR_full.pdf Giriș Tarihi: 12.06.2016

5. Jones KV, Asscher AW. Urinary tract infection and vesicourethral reflux. In: Edelman CM (editor). Pediatric Kidney Disease, 2nd ed, Boston, Little Brown; 1992.p.1943-1991.

6. Schlager TA, Dilks S, Trudell J. et al. Bacteriuria in children with neurogenic bladder treated with intermittent catheterization: natural history. J Pediatr. 1995;126:490-496.
7. Kanaheswari Y, Kavitha R, Rizal AM. Urinary tract infection and bacteriuria in children performing clean intermittent catheterization with reused catheters. Spinal Cord. 2014 Nov 25.

8. Wyndaele JJ, De Ridder D, Everaert K, et al. Evaluation of the use of Urocath-Gel catheters for intermittent self-catheterization by male patients using conventional catheters for a long time Spinal Cord. 2000; 38: 97-99.

9. Bakke A: Clean intermittent catheterization. Physical and psychological complications. Scand J Urol. 1993; 150: 69.

10. Hellstrom P, Tammela T, Lukkarinen O, et al: Effica- cy and safety of clean intermittent catheterization in adults. Eur Urol. 1991; 20: 117-121.

11. De Ridder DJ, Everaert K, Fernández LG, et al. Intermittent catheterisation with hydrophilic-coated catheters (SpeediCath) reduces the risk of clinical urinary tract infection in spinal cord injured patients: a prospective randomised parallel comparative trial. Eur Urol. 2005; 48: 991-995.

12. Heard L, Buhrer R. How do we prevent UTI in people who perform intermittent catheterization? Rehabil Nurs. 2005; 30: 44-45, 61.

13. Schmidt B, Copp HL. Work-up of Pediatric Urinary Tract Infection. Urol Clin North Am. 2015; 42: 519-526.

14. Saint S, Chenoweth CE. Biofilms and catheter-associated urinary tract infections. Infect Dis Clin North Am. 2003;17: 411432 .

15. Herz D, Merguerian P, McQuiston L. Continuous antibiotic prophylaxis reduces the risk of febrile UTI in children with asymptomatic antenatal hydronephrosis with either ureteral dilation, high-grade vesicoureteral reflux, or ureterovesical junction obstruction. J Pediatr Urol. 2014; 10: 650-654.

16. Kaye IY, Payan M, Vemulakonda VM. Association between clean intermittent catheterization and urinary tract infection in infants and toddlers with spina bifida. J Pediatr Urol. 2016 Mar 4.

17. Yang SH, Lee YS, Lin FH, et al. Chitosan/poly (vinyl alcohol) blending hydrogel coating improves the surface characteristics of segmented polyurethane urethral catheters. J Biomed Mater Res B Appl Biomater. 2007; 83: 304-313. 